(12.88\%) nitrile, and 43 (22.16\%) PVC gloves. Glove-induced skin symptoms were reported in 46 (23.71\%) subjects. On-site examination showed 59 (30.41\%) subjects with skin changes due to wet work or wearing gloves.

Sensitisation to latex or rubber additives was recorded in medical records of $18(9.27 \%)$ subjects. At the time of the survey, skin condition with all subjects was graded good by OHP or hasn't been checked. None has been diagnosed with OCD nor has been introduced to possibility of having one despite the fact that 59 subjects met the preconditions for OCD.

Conclusion Importance of prevention is emphasised while periodic health examinations performed by OHPs show weak efficacy in recognising OCD. Modified EvaHair and NOSQ 2002 questionnaire translated into Croatian were found to be valuable tools in detecting vulnerable individuals with high probability of having occupational contact dermatitis. Further evaluations are needed.

\section{DIFFERENCES IN MUSCULOSKELETAL COMPLAINTS AND DAILY FUNCTIONING IN CROATIAN NURSES EMPLOYED IN CHILD AND ADULT CARE - A CROWN STUDY}

${ }^{1}$ Denis Lisica Mandek*, 'Marija Bubaš, ${ }^{1}$ Helena Koren, ${ }^{2}$ Anica Prašnjak, ${ }^{1}$ Ana Bogadi Šare, ${ }^{1}$ Marija Zavalić. 'Croatian Institute for Health Protection and Safety at Work, Zagreb, Croatia; ${ }^{2}$ Croatian nurses and medical technicians trade union, Zagreb, Croatia

\subsection{6/oemed-2018-ICOHabstracts.950}

Introduction In 2014 a CROWN (Croatia, Workability, Nurses) study was conducted in Croatian nurses employed in clinical hospitals to determine general health status, physical and psychosocial health of nurses, prevalence and distribution of hand eczema and musculoskeletal symptoms and their influence on daily functioning. Data for musculoskeletal complaints and daily functioning with nurses employed in child and adult care will be shown.

Methods A Nordic standardised questionnaire for evaluation of musculoskeletal complaints accompanied with Lickert scale for self-evaluation of complaints and a Disability of arm, shoulder and hands (DASH) questionnaire for daily functioning, were used for this part of research in 115 nurses from three large clinical hospitals for children and two large clinical centres for adults. In both groups, the analysis of musculoskeletal pain (sites, frequency) and daily functioning will be compared to duration of work experience, number of patients, patients' weight and nurses' general health.

Results The prevalence rate of musculoskeletal complaints among our cohorts of nurses was $95 \%$ in child care, and $98,6 \%$ in adult care. Lower back pain and neck pain were the most frequent complaints in both groups. Lower back pain had the highest influence on daily functioning. Other comorbidity and problems in daily functioning in both groups will be shown.

Conclusion The prevalence rate for musculoskeletal complaints in this study was very high, higher then reported in similar other studies. That has confirmed the great need for analysing reasons for such a high prevalence of complaints, and taking actions which will reduce their contributing factors and influence on daily functioning. Although the nurses are highly aware of this problem a need exists for formal training in ergonomics, maintenance of adequate posture and taking micro-breaks in reducing WRMDs.

\section{AUDIT OF STAFF ATTITUDES TO INFLUENZA IMMUNISATION AND THE FACTORS WHICH MAY ENCOURAGE OR PROHIBIT UPTAKE}

Purcell Aisling*, O’Reilly Ann, N Tuohy, S Bulfin. St. Vincent's University Hospital, Dublin, Ireland

\subsection{6/oemed-2018-ICOHabstracts.951}

Introduction Influenza immunisation is offered and recommended to all staff in St. Vincent's University Hospital. While uptake has improved, the overall proportion of staff not immunised remains of concern.

The department of occupational health, infectious diseases and clinical audit collaborated to audit the attitudes of staff to influenza immunisation in 2015/2016. The results informed quality improvements for the 2016/2017 campaign e.g. increased information sessions and additional mobile 'out-ofhours' clinics. A re-audit was subsequently carried out.

Methods Hard copy and email questionnaires were distributed to all staff, 301 questionnaires were completed.

Result Clinical staff accounted for $75 \%$ of respondents in $2016 / 2017$ compared to $63 \%$ in $2015 / 2016$. Sixty-four per cent of respondents were previously immunised, demonstrating immunised staff were more likely to complete the audit, particularly doctors, allied healthcare professionals and management/administration staff.

The top 3 reasons for immunisation were 'it's what's recommended', 'protect myself from becoming unwell' and 'protect family members'. This is consistent with the previous audit, apart from one, where respondents cited 'protect my patients' over 'protect my family members'.

Ninety-seven per cent of previously immunised respondents agreed they would be immunised during this influenza season and $82 \%$ felt staff should be immunised. They were more likely to agree it should be mandatory for staff. Information about influenza and mobile clinics were the top 2 reasons chosen to help increase immunisation uptake, for immunised and non-immunised respondents.

Thirty-five per cent of respondents were not previously immunised and the top 2 reasons were 'I can manage the flu myself' and 'I am worried about side effects'. Of those, 52\% felt staff should be immunised, suggesting dissonance in this group. Compared to the previous audit, they were more likely to be immunised during 2016/2017, more likely to agree that staff should be immunised and that immunisation should be mandatory for staff. They were also more likely to associate the lack of information and the absence of mobile clinics as reasons for poor uptake.

Conclusion This audit implies providing increased, focused information and additional mobile clinics directly increases the rate of immunisation uptake. However despite this, respondents refer to the need for more information and mobile clinics, demonstrating that influenza immunisation is a perfect case of a complex adaptive system. Focusing on the method of communicating information and a peer vaccinator programme might enhance the next campaig. 